\title{
PROCESS AND SYSTEMS Lessons post-COVID from national and international approaches to safety and quality in healthcare
}

\author{
Authors: Niki O'Brien, ${ }^{A}$ Mike Durkin ${ }^{B}$ and Peter Lachman ${ }^{C}$
}

\begin{abstract}
The COVID-19 pandemic has been a challenge as well as an opportunity for healthcare. The pandemic has exposed the inherent weaknesses in health systems globally while, at the same time, revealing strengths on which post-pandemic health systems can be built. We propose lessons on improving quality and safety post-pandemic from a global perspective based on recent policy publications and our global experience. Nine possible lessons are discussed. These lessons can ensure that healthcare does not return to the old normal, but rather builds on what we have learnt as we deliver on the Sustainable Development Goals and universal health coverage. Quality and safety are an essential component of healthcare strategy. Postpandemic systems require a transparent compassionate culture, with integration of care at its core. The workforce must be trained in the skills to improve care, and patient and healthcare worker protection (both physically and psychologically) needs to be a given. Any development of systems will best be coproduced with the people who receive and deliver care in an equal partnership. Finally, the new systems need to be conscious of emerging threats (such as the challenge of climate change), building sustainable health systems that also address the structural inequities that currently exist.
\end{abstract}

KEYWORDS: COVID-19, patient safety, health systems, Healthcare workers, quality

DOI: 10.7861/fhj.2021-0158

\section{Introduction}

Health systems require safety and quality to be at the core of their activities to implement universal health coverage (UHC) and deliver Sustainable Development Goals (SDGs). ${ }^{1}$ The safe delivery of high-quality healthcare is a challenge in many countries. In 2018 , three reports outlined the state of healthcare quality and

Authors: A policy fellow in global health, Institute of Global Health Innovation, London, UK and Imperial College London, London, UK; ${ }^{B}$ senior advisor on patient safety policy and leadership, and academic lead, Global Patient Safety Collaborative, London, UK; ' lead faculty quality improvement programme, Royal College of Physicians of Ireland, Dublin, Ireland patient safety globally, with lessons and recommendations for the future. ${ }^{2-4}$ Before any meaningful action could be taken, the COVID-19 pandemic disrupted normal activities and health systems worldwide have been adversely affected, no matter where they are located.

As we emerge from the pandemic, the question is: "How can we develop resilient services that can respond to crises and remain safe, effective and person centred?' The World Health Organization (WHO) Global Patient Safety Action Plan, released in August 2021, is the first major report to position patient safety within a post-COVID-19 world. ${ }^{5}$ This action plan, as well as the pre-COVID-19 reports, provide guidance and, here, we distil the key lessons from these reports to be applied in the post-COVID-19 era, with examples from the global community based on our experience. We propose nine lessons and share an example for each that have been delivered (Box 1).

\section{Lesson 1: The future for quality is bound up in} managing complex systems

Over the past 20 years, it has been recognised that an understanding of how the different component parts of

Box 1. Nine global lessons post-COVID-19 pandemic

Systems: The future for quality is bound up in managing complex systems.

Strategy: Quality and safety are an integral part of healthcare strategies.

Learning: Develop national learning systems with transparency as a core value.

Workforce: Develop the future workforce to deliver the strategy.

Safety: Ensure the safety of patients and healthcare workers with respect and kindness.

$>$ Co-production: Codesign solutions with people receiving and delivering care.

Integration: Ensure integration of care.

> Sustainability: Recognise sustainable healthcare as a new domain of quality.

Equity: Address structural inequity and the social determinants of health. 


\section{For people}

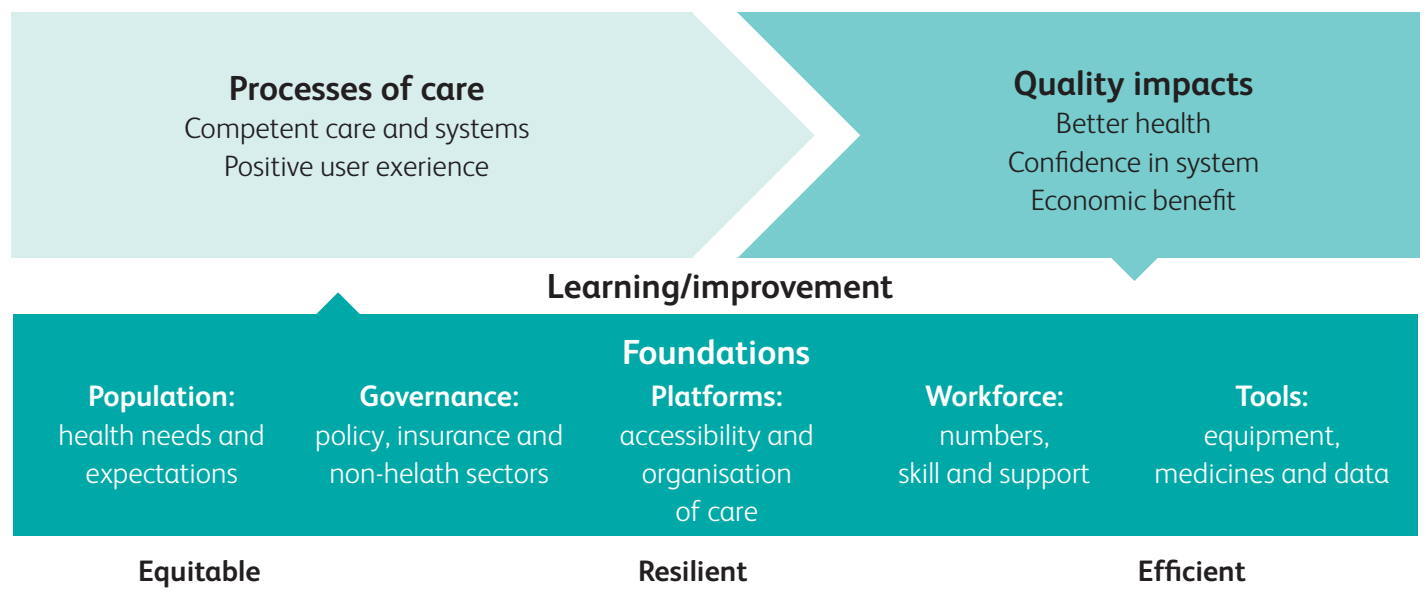

Fig 1. High-quality health system framework. Adapted with permission from Kruk ME, Gage AD, Arsenault C et al. High-quality health systems in the Sustainable Development Goals era: time for a revolution. Lancet Glob Health 2018;6:e1196-252 (Licence: CC BY 4.0).

healthcare interact is essential. The reports concur on the need for improved quality measurement, learning and improvement, alongside integration and coordination across the healthcare continuum within a systems framework. ${ }^{2-4}$ In Fig 1, the way that we can conceptualise systems thinking for quality healthcare is shown. $^{3}$

The systems approach to improvement requires accountability from leaders to tackle challenges such as corruption, inequity and

Case study 1. Developing strategies for quality in complex systems in Ethiopia

The Ethiopian Ministry of Health (MOH) first published a comprehensive quality strategic plan in 2016 as part of a systems approach to quality and safety with the aim to provide 'a roadmap for addressing key quality challenges and for accelerating the improvement of health care quality nationwide. The ultimate aim is to consistently improve the outcomes of clinical care, patient safety, and patient-centeredness, while increasing access and equity for all segments of the Ethiopian population, by 2020.'7 Aligned to the strategy was a learning plan to up-skill healthcare workers in quality improvement methodology. In 2021, a revised strategic plan has been developed and will be implemented shortly, building on the lessons learnt with a strong emphasis on safety, co-production and integration. Another example of how a country like Ethiopia can have ambitious goals is the 2020/21 - 2024/25 strategic plan for early childhood development. ${ }^{8}$ The strategy provides a detailed roadmap and framework for the $\mathrm{MOH}$ to ensure the effective and integrated implementation of national policy in this area. The 6th annual quality summit, held in May 2020, demonstrated how fa the process has developed by bringing stakeholders and experts involved in healthcare in quality and safety management. ${ }^{9}$ As a next step, the event organisers aim to implement and monitor identified lessons and inputs gained in the summit and prepare for additional summits in the future. ${ }^{9}$ climate change. Quality and safety in fragile states is particularly difficult. ${ }^{6}$ Nevertheless, there are examples of implementing quality strategies in low- and middle-income country (LMIC) settings that offer learnings, as shown in Case study $1 .^{7-9}$

\section{Lesson 2: Quality and safety are an integral part of the healthcare strategies}

The WHO framework on how to develop a quality strategy consists of eight steps (Fig 2) with supporting toolkits. ${ }^{10}$

These can be supplemented by a framework from the European Observatory, which integrates improvement methodology around three dimensions of quality: effectiveness, safety and responsiveness. ${ }^{11}$

The lesson from these high-level strategic frameworks is that quality and safety must be at the core of health services, within a foundation of improvement and implementation science. Case study 2 demonstrates the translation of strategy to implementation on a national level. ${ }^{12-14}$

\section{Lesson 3: Develop national learning systems with transparency as a core value}

Once a strategy has been developed, it requires a learning system based on the values of transparency and openness. A focus on what works well, as well as clinical incidents and near misses, supports greater accountability and fosters safety and quality. ${ }^{15}$ For example, the National Reporting and Learning System (NRLS) in Thailand, developed as part of a national policy on patient and personnel (2P) safety has collected more than 1,300,000 incident reports utilising handheld devices, web and cloud-based technology between 2018 and 2020. Greater transparency can also help to counter potential corruption. ${ }^{16}$

In the quality learning system, research on safety and quality should be prioritised to build a firm evidence base of what works, using both the traditional research methodology as well as alternative ways of learning in real time. ${ }^{15,17}$ Case study 3 demonstrates how one can learn in times of crisis. ${ }^{18-20}$ 


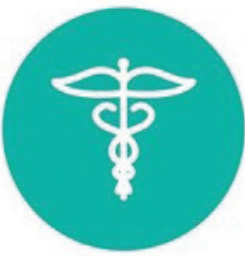

National health priorities

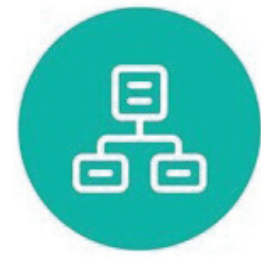

Governance and organisational structure

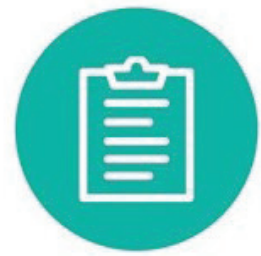

Local definition of quality

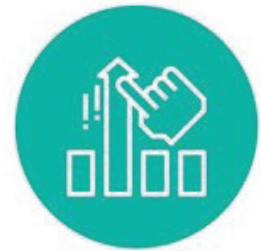

Improvement methods and interventions

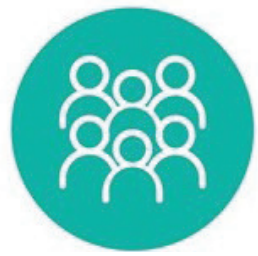

Stakeholder mapping and engagement

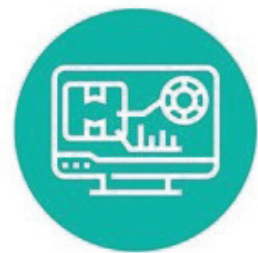

Health management information systems and data systems

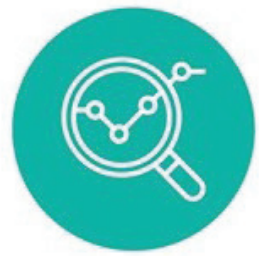

Situational analysis



Quality indicators and core measures

Fig 2. The eight elements of the World Health Organization national quality policy and strategy. Adapted with permission from World Health Organization. Handbook for national quality policy and strategy: a practical approach for developing policy and strategy to improve quality of care. Geneva: WHO, 2018 (Licence: CC BY-NC-SA 3.0 IGO).

\section{Lesson 4: Develop the future workforce to deliver the strategy}

The development of leaders in patient safety and quality is essential to improve the quality and safety of care. Education for safety is a key priority of the WHO action plan that notes that programmes targeting undergraduate and postgraduate students, and other medical professionals, are essential interventions. ${ }^{5}$

Case study 2. A national programme to improve quality and safety in Oman

National programmes to improve quality and safety are often varied given the wide scope of possible initiatives. In the World Health Organization (WHO) Eastern Mediterranean region, the Patient Safety Friendly Hospital Initiative (PSFHI), a tool formulated by the WHO to achieve optimal patient safety in hospitals, was implemented in Oman from 2016. ${ }^{12}$ The PSFHI manual provides the necessary tools for assessing hospitals, with a section on patient safety standards and another on hospital assessment tools. Assessed domains include 'leadership and management', 'patient and public involvement', 'safe evidencebased clinical practices', 'safe environment' and 'lifelong learning'. Hospitals are scored by level based on compliance with the patient safety standards. Participant hospitals showed advanced patient quality care and safety measurements as compared with hospitals that did not participate in the programme. ${ }^{13}$ Following the launch of the PSFHI in Oman, almost $90 \%$ of the main hospitals are now enrolled. ${ }^{14}$ Further information and data on the impact of the PSFHI in Oman can be found on the WHO Regional Office website and in published commentary and analysis papers. $^{12-14}$
Case study 3. Learning and developing preparedness approaches from periods of crisis

Early response to the COVID-19 pandemic in Sierra Leone focused on key management and preparedness lessons learned from the Ebola epidemic (2014-2016): daily coordination briefings at the national emergency operations centre, isolation of positive cases, contact tracing and isolation of those exposed. ${ }^{18,19}$ Health systems around the world have adopted similar measures. The management of misinformation spread during the Ebola epidemic also aided the health system in developing strategies to share accurate information on COVID-19 through media outlets, a lesson that governments globally may have heeded sooner given the challenges of misinformation that have been widely reported since the pandemic's onset. ${ }^{18}$ Sierra Leone's measures, based on prior lessons learned and preparedness, were effective in curbing COVID-19 cases and deaths in a country whose health system is still weakened post-Ebola. These successes are stark in comparison to other African nations where cases and deaths have been markedly higher. ${ }^{19}$ While it is important to recognise the challenges in accurate reporting of COVID-19 cases and deaths in low- and middle-income country settings, existing evidence shows a large variation in case and death rates across sub-Saharan Africa; for example, South Africa has recorded the highest death rate per population (151.2 deaths per 100,000). ${ }^{20}$ Liberia (which neighbours Sierra Leone and was similarly impacted by the 2014-2016 Ebola outbreak) has recorded 5.7 deaths per 100,000 population, as compared with Sierra Leone's 1.5 deaths per $100,000 .^{21}$ The key learning is that one can translate lessons from one type of infection to another, while realising they have different needs, but the response principles are similar. ${ }^{18,19}$ 
Case study 4. Developing future leaders in patient safety to deliver solutions

The International Society for Quality in Healthcare (ISQua) has a leadership programme for clinicians in low- and middle-income countries (LMICs), which is designed to provide patient safety fellows with training in the theory of patient safety science in interventions to improve patient safety. ${ }^{23} \mathrm{~A}$ further programme is run by the Patient Safety Movement Foundation (Healthcare Safety Fellowship) that aims to develop lifelong global patient safety leaders from a variety of backgrounds, locations and disciplines. ${ }^{24}$ In both programmes, the learning experience is virtual, allowing global reach and participation. Fellows are mentored by experts from their region and, if in LMICs, from the upperincome country as well. The fellowship introduces the learners to principles of patient safety, human factors, high reliability and leading change.

Educational resources and activities can be shared globally, especially in areas not previously exposed to improvement science. ${ }^{22}$ Case study 4 demonstrates examples of capacity building in LMICs. ${ }^{23,24}$

\section{Lesson 5: Ensure the safety of patients and healthcare workers with respect and kindness}

The WHO has designated 2020-2030 as the decade of patient safety. ${ }^{25}$ The pandemic demonstrated the importance of patient safety as well as protecting the wellbeing of all health workers, recognised by the 2020 WHO World Patient Safety Day. ${ }^{26,27}$ Organisations and industries outside healthcare value investing in the psychological safety of their workforce. ${ }^{28}$ A systems approach to healthcare worker burnout is essential. ${ }^{29}$ Leaders in healthcare need to recognise and support the physical and mental health needs of the global healthcare worker population. ${ }^{30}$ Compassionate leadership aims to supports all leaders and workers at every level of the organisation. ${ }^{31}$ The need for a kind and caring approach, as opposed to a technical approach to healthcare has become apparent. ${ }^{32-34}$ This is a challenge in

Case study 5. Ensuring kindness and respect are part of systems and processes

In the complexity of healthcare, it is apparent that respect, compassion and kindness are essential components to develop safe, effective and person-centred care clinical teams. The concept of kindness is not new, it is fundamental to care in many cultures eg in India and across Africa. Recently the focus on kindness has grown in upper-income countries; for example, in Leuven, Belgium, a programme called Mangomoments has focused on facilitating unexpected small acts of kindness by healthcare workers to patients in their care. ${ }^{37}$ Research on the acts of kindness demonstrated improved patient and family experience, which also facilitated adherence to therapy and led to a positive perception on the healing process. ${ }^{38}$ Trust between care giver and care receiver was enhanced. There were positive effects for professionals, including joy in work, less risk of burnout and the development of a positive work environment. ${ }^{39}$ This, in turn, facilitates psychological safety. ${ }^{38}$
Case study 6. Co-production in Scotland

A project by NHS Highland to codesign the use of NHS Near Me, an online service enabling video consultations with specialists in patients' homes, offers an example of co-production in practice. The project led to 25 adaptations being made to the appointment process, as patients had the opportunity to design the healthcare delivery tool that best suited their needs. ${ }^{43}$ Developing policy, guidance and tools towards co-production and patient, carer and community inclusion must be met with a commitment to the principles of co-production across the healthcare sector, and crucially by senior leadership. ${ }^{44,45}$ Critically, patient, carer and community participation must be representative of the communities served.

settings where hierarchy is the paradigm, with inappropriate use of professional, gender, racial and religious power dynamics. ${ }^{35,36}$ Case study 5 illustrates how safety can be improved through collaboration. ${ }^{37-39}$

\section{Lesson 6: Co-design solutions with people receiving and delivering care}

People, whether they are patients, providers or carers, must play a central role in the development of healthcare services. Coproduction implies the sharing of power, which is a challenge for health systems but can be very valuable. ${ }^{40}$ An NHS England study of 17 organisations found that patient leaders can focus more clearly on what patients want. ${ }^{41}$ In the UK, a range of co-production policy and guidance, including the co-production model, have been developed (Case study 6). ${ }^{42-45}$

\section{Lesson 7: Ensure integration of care}

The Lancet Commission identified integration of care as a priority to reduce the burden on patients and increase safety, quality and efficiency across a health system. ${ }^{3}$ Practical attempts at integration of care, particularly in LMICs, have had mixed results as the focus has been on increasing access and efficiency, rather than integrating existing services and patient experience. ${ }^{2}$ National quality planning processes should integrate quality improvement into services. ${ }^{46}$ Digital solutions may offer an opportunity for integration though a range of challenges with inequity must be considered and addressed.

The WHO published a report with examples of integration of care across high-, middle- and low-income health systems. ${ }^{47}$ Examples include the integration of community-owned primary care health networks in Mali (where there has been a measurable increase in curative care episodes, greater antenatal provision and improved vaccination coverage) and the integration of HIVIAIDS and tuberculosis programmes to disadvantaged communities in Kenya. Case study 7 illustrates an example of integration in an upper-income country. ${ }^{48-51}$

\section{Lesson 8: Recognise sustainable healthcare as a new domain of quality}

As health systems around the world are increasingly affected by the impact of climate change, sustainable healthcare must be built into processes in quality improvement planning. This is important for health systems globally, but particularly for 
Case study 7. Integration of care to better support the elderly in Singapore

In response to an ageing population, the Singaporean health system has transformed the way it delivers healthcare to the elderly with a multidisciplinary, person-centric approach and joining up care services. ${ }^{48}$ Primary care services have been extended with networks between hospitals and local primary care providers (including dental and allied health professionals) to provide family-oriented care. Social support has been improved for the elderly through formalised networks linking government agencies, health providers and community groups. ${ }^{48} \mathrm{~A}$ key lesson is the importance of effective collaboration in the Ministry of Health for education and training, healthcare finance reforms, robust health information systems, responsiveness to emergent behaviours and the ability to self-organise and adapt to unexpected situations. ${ }^{49,50}$ Challenges include scale up of successful pilot models, enhancing jobs and skills, and maintaining affordability. ${ }^{51}$

LMIC systems. Climate change will add additional pressures to maintaining the health of populations, the ability to provide health services and the management of limited financial resources, all of which are essential to achieve UHC; for example, climate change will increasingly cause periods where health services will be disrupted by facilities damage, disrupted supply chains and workforce shortages as staff are affected by climate events. ${ }^{51}$

Sustainability, in the healthcare context, refers to the capacity of a health service to deliver healthcare over time, with consideration for future generations. ${ }^{52}$ Training of health professionals on 'resource stewardship' can drive decision making and resource allocation. ${ }^{52}$ Low-carbon alternatives (including minimising the waste of medications, consumables and energy) are possible. ${ }^{52}$ In the context of the COVID-19 pandemic, it has been estimated that, globally, 3.4 billion single-use face masks/face shields are discarded daily, reversing momentum around discouraging the consumption of single-use plastics in healthcare. ${ }^{53}$ Case study 8 illustrates the role of stakeholder collaboration in driving sustainable healthcare. ${ }^{54-56}$

\section{Lesson 9: Address structural inequity and the social determinants of health}

Societal inequities have far reaching implications on population health. ${ }^{57}$ Wilkinson and Pickett highlight the health implications of inequity, finding a strong relationship between higher prevalence of mental illness and income inequity across 11 of the 12 countries analysed. ${ }^{58}$ Similarly, life expectancy and infant mortality in highincome countries was found to be related to inequity, with health being poorer for the whole society in countries where inequity is high. ${ }^{58}$

The COVID-19 pandemic exposed inequity in healthcare globally and nationally. Major health inequities have been demonstrated across health systems. ${ }^{59}$ Mortality rates from COVID-19 were substantially higher among ethnic minority groups in the UK, with the rate of death among Black men 4.7 times higher than those from a White ethnic group. ${ }^{60}$ Globally, the race for vaccinations in highincome countries has led to disparities in the proportion of inoculated populations between high-, middle- and low-income countries. ${ }^{61}$

Two reports, one just prior to the pandemic and one 10 months into the pandemic, document the social determinants impacting on health. ${ }^{62,63}$ A report from the NHS Race and Health Observatory calls for
Case study 8. Driving sustainable healthcare research, policy and innovation within a supportive ecosystem

Sustainable healthcare is a growing area of research and policy in the Nordic region, considered a global frontrunner in this area. 54,55 The legislative and policy environment helps facilitate this; for example, all hospitals in Norway are certified in the environmental management system (ISO 14001) and most hospitals report on sustainability. ${ }^{55}$ The Nordic Center for Sustainable Healthcare (NCSH), a network involving stakeholders, organisations, projects and expertise in the area of sustainable healthcare, with the goal of creating a more sustainable healthcare sector focused on developing sustainable healthcare in the Nordic region. ${ }^{56}$ The NCSH focuses operations around three core areas: sustainable hospitals, sustainable behaviour and sustainable technologies; for example, larger Nordic hospitals have established technical innovation departments that facilitate the development of sustainable healthcare initiatives focused on the running of the hospital, care and diagnostics, as well as the sustainability of the building itself (such as the installation of solar cells to heat hospitals all year round). The organisation has facilitated stakeholder mapping and effectively brought together stakeholders in the health sector around this topic to advance research and policy development. ${ }^{54}$

proactive leadership, targeted interventions and better use of data. ${ }^{64}$ Hirschhorn et al recommend that we disaggregate data to reveal inequity and then design services to address the inequity at scale. ${ }^{65}$

The future workforce must be made conscious of inherent bias and structural inequity, as well as the potential for bias in new health technologies and applications (eg artificial intelligence). ${ }^{66}$ Case study 9 outlines the changing research agenda towards addressing health inequities. ${ }^{49,50,67-71}$

\section{Conclusion}

The onset of the COVID-19 pandemic has strained health systems globally, increasing the challenges in providing safe quality care. The reports we have referenced offer a solution, although implementation

Case study 9. Funding to support research into COVID-19 health inequities

The importance of investing in health research that reflects the disease burden and healthcare priorities in ethnic minority groups has been highlighted through the COVID-19 pandemic as health inequities associated with COVID-19 have been widely reported. ${ }^{49,50}$ In the UK and USA, major funding bodies are recognising the value and importance of funding research into health inequities towards addressing structural inequity and the social determinants of health. The UK National Institute for Health Research (NIHR) and UK Research and Innovation (UKRI) launched a funding call for research to understand the disproportionate death rate from COVID-19 in minority ethnic groups in April 2020 worth $£ 4.3$ million. ${ }^{67,68}$

In the USA, the National Institutes of Health (NIH) launched a funding call in August 2021 focused on the social, behavioural, economic impact of COVID-19 in underserved and vulnerable populations. ${ }^{69}$ Similarly, the Institute of Healthcare Improvement has developed educational resources on the topic of equity. ${ }^{70,71}$ 
will be a challenge. ${ }^{2-5,72}$ The pandemic shed new light on the value and benefits of active safety and quality improvement in periods of crisis. It is an opportunity for us to think differently and to redesign our services to be person centred, eco-friendly and safe. ${ }^{73}$ This also requires proactively responding to the social determinants that define health and outcomes for many people.

Going forward, as health systems address the long-term effects of COVID-19, global learning is now more critical than ever to drive continued improvement. The global health community can learn from best practice, adapting interventions and implementation to their own context to facilitate improvement.

\section{References}

1 World Health Organization. Universal health coverage (UHC). World Health Organization, 2021. www.who.int/news-room/fact-sheets/ detail/universal-health-coverage-(uhc) [Accessed 24 August 2021].

2 National Academies of Sciences, Engineering, and Medicine. Crossing the global quality chasm: Improving health care worldwide. The National Academies Press, 2018.

3 Kruk ME, Gage AD, Arsenault $C$ et al. High-quality health systems in the Sustainable Development Goals era: time for a revolution. Lancet Glob Health 2018;6:e1196-252.

4 World Health Organization, OECD, The World Bank. Delivering quality health services: A global imperative for universal health coverage. Geneva: WHO, 2018.

5 World Health Organization. Global Patient Safety Action Plan 2021-2030: Towards eliminating avoidable harm in health care. Geneva: WHO, 2021.

6 World Health Organization. Quality of care in fragile, conflictaffected and vulnerable settings: tools and resources compendium. Geneva: WHO, 2020

7 Federal Democratic Republic of Ethiopia Ministry of Health. Ethiopian National Health Care Quality Strategy 2016-2020: Transforming the Quality of Health Care in Ethiopia. Ministry of Health Ethiopia, 2016. http://repository.iifphc.org/bitstream/ handle/123456789/268/Ethiopian \% 20National \% 20Health \% 20 Care \% 20Quality \% 20Strategy.pdf? sequence=1 \&isAllowed $=y$ [Accessed 06 September 2021].

8 Ministry of Health Ethiopia. National health sector strategic plan for early childhood development in Ethiopia: 2021/21-2024/25. Ministry of Health Ethiopia, 2020. www.unicef.org/ethiopia/ media/3701/file/NATIONAL $\%$ 20HEALTH $\%$ 20SECTOR $\% 20$ STRATEGIC \% 20PLAN \% 20FOR \% 20EARLY \% 20CHILDHOOD \% 20 DEVELOPMENT \% 20IN \% 20ETHIOPIA \% 20.pdf [Accessed 06 September 2021].

9 Ministry of Health Ethiopia. The $6^{\text {th }}$ Ethiopian Annual Health care quality and safety summit: Summit Proceeding May 6-7, 2020. Ministry of Health Ethiopia, 2020. https:/qualityofcarenetwork.org/ sites/default/files/2021-06/Ethiopia \% 20National \% 20Quality \% 20 and $\%$ 20safety $\%$ 20summit $\% 202021 \%$ 20Proceedings.pdf [Accessed 06 September 2021].

10 World Health Organization. Handbook for national quality policy and strategy: a practical approach for developing policy and strategy to improve quality of care. Geneva: WHO, 2018.

11 European Observatory on Health Systems and Policies. Improving healthcare quality in Europe: Characteristics, effectiveness and implementation of different strategies. European Observatory on Health Systems and Policies, 2019.

12 Al-Mandhari A, Al-Farsi S, Al-Barwani S et al. Developing patient safety system using WHO tool in hospitals in Oman. Int ] Qual Health Care 2018;30:423-8.

13 Letaief M, Alboksmaty A. A commentary article about the implementation and advancement of the Patient Safety Friendly Hospital Initiative (PSFHI) in the Eastern Mediterranean Region.
World Hospitals and Health Services 2019:55:4-6.

14 World Health Organization. Patient Safety Friendly Hospital Initiative in Oman. WHO, 2018. www.emro.who.int/omn/omannews/patient-safety-friendly-hospital-initiative-in-oman.html [Accessed 19 October 2021].

15 National Steering Committee for Patient Safety. Safer Together: A National Action Plan to Advance Patient Safety. Institute for Healthcare Improvement, 2020. www.ihi.org/SafetyActionPlan [Accessed 28 July 2021].

16 Mackey TK, Cuomo RE. An interdisciplinary review of digital technologies to facilitate anti-corruption, transparency and accountability in medicines procurement. Glob Health Action 2020;13(sup1):1695241.

17 Greenhalgh T. Will COVID-19 be evidence-based medicine's nemesis? PLoS Med 2020;17:e1003266.

18 Parmley LE, Hartsough K, Eleeza O et al. COVID-19 preparedness at health facilities and community service points serving people living with HIV in Sierra Leone. PLOS ONE 2021;16:e0250236.

19 Maxmen A. Ebola prepared these countries for coronavirus - but now even they are floundering. Nature 2020;583:667-8.

20 Richards R. Evidence on the accuracy of the number of Covid-19 infections and deaths in Lower-Middle Income countries. Knowledge, Evidence and Learning for Development (K4D), 2020. https://opendocs.ids.ac.uk/opendocs/bitstream/ handle/20.500.12413/15576/856_Accuracy_of_Covid19_Data_in LMICs.pdf?sequence=5\&isAllowed=y [Accessed 19 October 2021].

21 John Hopkins University Coronavirus Research Center. Mortality Analyses. John Hopkins University. https://coronavirus.jhu.edu/ data/mortality [Accessed 19 October 2021].

22 Ramaswamy R, Chirwa T, Salisbury K et al. Developing a field of study in implementation science for the Africa region: The WitsUNC AIDS Implementation Science Fogarty D43. Pedagogy in Health Promotion 2020;6:46-55.

23 International Society for Quality in Health Care. Scholarship opportunities. ISQua, 2021. https://isqua.org/scholarships.html [Accessed 28 July 2021].

24 Patient Safety Movement Foundation. Healthcare Safety Fellowship. Patient Safety Movement Foundation, 2021. https:// patientsafetymovement.org/events/education/healthcare-safetyfellowship [Accessed 28 July 2021].

25 World Health Organization. Update from the Seventy-fourth World Health Assembly - 28 May 2021. WHO, 2021. www.who.int/news/ item/28-05-2021-update-from-the-seventy-fourth-world-healthassembly-28-may-2021 [Accessed 24 August 2021].

26 Shaw A, Flott K, Fontana $\mathrm{G}$ et al. No patient safety without health worker safety. Lancet 2020;396:1541-3.

27 World Health Organization. World Patient Safety Day. WHO, 2021. www.who.int/campaigns/world-patient-safety-day/2020 [Accessed 28 July 2021].

28 Edmonson A. The Fearless Organization. Hoboken: John Wiley \& Sons, 2019.

29 National Academies of Sciences, Engineering, and Medicine. Taking Action Against Clinician Burnout: A Systems Approach to Professional Well-Being. National Academies Press, 2019.

30 O'Brien N, Flott K, Durkin M. COVID-19: leadership on the frontline is what matters when we support healthcare workers. Int ] Qual Health Care 2021:33:mzaa153.

31 West MA, Chowla R. Compassionate leadership for compassionate health care. In: Gilbert P (ed). Compassion: concepts, research and applications. London: Routledge, 2017.

32 Campling P. Reforming the culture of healthcare: the case for intelligent kindness. BJPsych Bull 2015;39:1-5.

33 Ballatt J, Campling P, Maloney C. Intelligent kindness: rehabilitating the welfare state. Cambridge University Press, 2020.

34 Allwood D, Koka S, Armbruster R et al. Leadership for careful and kind care. BM] Leader 2021 [Epub ahead of print]. 
35 Vlassoff C. Addressing mental health from a gender perspective. In: Davidson $\mathrm{L}$ (ed). The Routledge handbook of international development, mental health and wellbeing. London: Routledge, 2019.

36 Braithwaite J, Clay-Williams R, Vecellio E et al. The basis of clinical tribalism, hierarchy and stereotyping: a laboratory-controlled teamwork experiment. BMJ Open 2016:6:e12467.

37 Mangomoment. What's a Mangomoment? Mangomoment.org https://mangomoment.org/english-2 [Accessed 19 October 2021].

38 Vanhaecht K, Van Bael E, Coeckelberghs E et al. Mangomoments preconditions and impact on patients and families, healthcare professionals and organisations: a multi-method study in Flemish hospitals. BMJ Open 2020;10:e034543.

39 Vanhaecht K. In search of Mangomoments. Lancet Oncol 2018;19:165

40 Batalden M, Batalden P, Margolis P et al. Coproduction of healthcare service. BMJ Qual Saf 2016;25:509-17.

41 NHS England. Improving Experience of Care through people who use services: How patient and carer leaders can make a difference. NHS, 2015. www.england.nhs.uk/wp-content/uploads/2013/08/ imp-exp-care.pdf [Accessed 28 July 2021].

42 NHS England. Co-production resources. NHS, 2021. www.england. nhs.uk/get-involved/resources/co-production-resources [Accessed 28 July 2021].

43 Beattie M, Morrison C, MacGilleEathain R, Gray N, Anderson J. Near Me at Home: codesigning the use of video consultations for outpatient appointments in patients' homes. BMJ Open Qual 2020;9:e001035.

44 Batalden P. Getting more health from healthcare: quality improvement must acknowledge patient coproduction - an essay by Paul Batalden. BMJ 2018;362:k3617.

45 Elwyn G, Nelson E, Hager A et al. Coproduction: when users define quality. BMJ Qual Saf 2020;29:711-6.

46 World Health Organization. Quality health services: a planning guide. Geneva: WHO, 2020.

47 World Health Organization. People-centred and integrated health services: an overview of the evidence: Interim Report. Geneva: WHO, 2015.

48 Brady E, Carmone A, Das S et al. Harnessing the power of networks of care for universal health coverage. Health Systems \& Reform 2020;6:2.

49 Nurjono M, Yoong J, Yap P et al. Implementation of integrated care in Singapore: a complex adaptive system perspective. Int J Integr Care 2018:18:4.

50 Ong SE, Tyagi S, Lim JM, Chia KS, Legido-Quigley H. Health systems reforms in Singapore: A qualitative study of key stakeholders. Health Policy 2018:122:431-43.

51 Roland J, Kurek N, Nabarro D. Health in the climate crisis: A guide for health leaders. Doha: World Innovation Summit for Health, 2020.

52 Mortimer F, Isherwood J, Wilkinson A, Vaux E. Sustainability in quality improvement: redefining value. FHJ 2018;5:88-93.

53 Benson N, Bassey D, Palanisami T. COVID pollution: impact of COVID-19 pandemic on global plastic waste footprint. Heliyon 2021:7:e06343.

54 Pereno A, Eriksson D. A multi-stakeholder perspective on sustainable healthcare: From 2030 onwards. Futures 2020;122;102605.

55 Eriksson D, Turnstedt L. Nordic Sustainable Healthcare. Nordic Innovation, 2019. http://norden.diva-portal.org/smash/record.jsf? pid=diva2 \%3A1346242\&dswid=875 [Accessed 09 September 2021]

56 Nordic Center for Sustainable Healthcare. Vision. NCSH, 2021. https://nordicshc.org/vision.html [Accessed 09 September 2021].

57 Goh S. Rapid response to Immortality of inaction on inequality: Say what you mean, mean what you say: inequality and inequity. BM] 2017;356:j556. www.bmj.com/content/356/bmj.j556/rr-8 [Accessed 28 July 2021].

58 Pickett K, Wilkinson R. The spirit level: why equality is better for everyone. London: Penguin Books, 2010.

59 Chin MH. Advancing health equity in patient safety: a reckoning, challenge and opportunity. BMJ Qual Saf 2021;30:356-61.
60 Office for National Statistics. Updating ethnic contrasts in deaths involving the coronavirus (COVID-19), England and Wales: deaths occurring 2 March to 28 July 2020. ONS, 2020. www.ons.gov. uk/peoplepopulationandcommunity/birthsdeathsandmarriages/ deaths/articles/updatingethniccontrastsindeathsinvolving thecoronaviruscovid19englandandwales/ deathsoccurring2marcht o28july2020\#overview-of-ethnic-group-breakdowns [Accessed 28 July 2021].

61 United Nations Department of Economic and Social Affairs. World economic situation and prospects as of mid-2021. United Nations, 2021. www.un.org/development/desa/dpad/wp-content/uploads/ sites/45/publication/WESP2021_UPDATE.pdf [Accessed 28 July 2021].

62 Marmot M, Allen J, Boyce T et al. Health Equity in England: The Marmot Review 10 Years On. London: Institute of Health Equity, 2020.

63 Marmot M, Allen J, Goldblatt P et al. Build Back Fairer: The COVID-19 Marmot Review. The Pandemic, Socioeconomic and Health Inequalities in England. London: Institute of Health Equity, 2020.

64 Robertson R, Williams E, Buck D et al. Ethnic health inequalities and the NHS: driving progress in a changing system. NHS Race and Health Observatory, 2021. www.nhsrho.org/publications/ethnichealth-inequalities-and-the-nhs [Accessed 19 August 2021].

65 Hirschhorn L R, Magge H, Kiflie A. Aiming beyond equality to reach equity: the promise and challenge of quality improvement $B M]$ 2021:374:n939.

66 Leslie D, Mazumder A, Peppin A et al. Does "AI" stand for augmenting inequality in the era of COVID-19 healthcare? BMJ 2021;372:n304.

67 National Institute for Health Research. NIHR and UKRI launch call for research on COVID-19 and ethnicity. NIHR, 2020. www.nihr. ac.uk/news/nihr-and-ukri-launch-call-for-research-on-covid-19-andethnicity/24658 [Accessed 06 September 2021].

68 National Institute for Health Research. Multimillion investment in new research projects to investigate higher COVID-19 risk among certain ethnic groups. NIHR, 2020. www.nihr.ac.uk/news/ multimillion-investment-in-new-research-projects-to-investigatehigher-covid-19-risk-among-certain-ethnic-groups/25333 [Accessed 06 September 2021].

69 National Institutes of Health. Active Funding Opportunities: Notice of Special Interest (NOSI): Social, Behavioral, and Economic Impact of COVID-19 in Underserved and Vulnerable Populations. NIH, 2021. https://grants.nih.gov/grants/guide/notice-files/NOT-MH-21-330. html [Accessed 06 September 2021].

70 Duong T, Silvashanker K. How to Address Equity as Part of COVID-19 Incident Command. Institute of Healthcare Improvement, 2020. www.ihi.org/communities/blogs/howto-address-equity-as-part-of-covid-19-incident-command [Accessed 06 September 2021].

71 Hart L, Wei E, Krouss M et al. Ingraining Equity into Quality and Safety: A System-Wide Strategy. Institute of Healthcare Improvement, 2020. www.ihi.org/communities/blogs/ingrainingequity-into-quality-and-safety-a-system-wide-strategy [Accessed 06 September 2021].

72 Braithwaite J, Vincent C, Garcia-Elorrio E et al. Transformational improvement in quality care and health systems: the next decade. BMC Med 2020;18,340.

73 Lachman P, Batalden P, Vanhaecht K. A multidimensional quality model: an opportunity for patients, their kin, healthcare providers and professionals to coproduce health. F1000Research 2021:9:1140.

Address for correspondence: Dr Peter Lachman, Royal College of Physicians of Ireland, No. 6 Kildare Street, Dublin 2, Ireland. Email: peterlachman@rcpi.ie

Twitter: @peterlachman; @Mike_Durks 